\title{
Simultaneous Optimization: Sectorization and Congolese Air Traffic Assignment by the Method of Preferential Reference of Dominance
}

\section{Michaël KIKOMBA KAHUNGU}

Institut Supérieur de Techniques Appliquées, ISTA/Kasangulu. RD Congo. michaelkikomba@yahoo.fr

\section{Rostin MABELA MAKENGO MATENDO}

Département de Mathématiques et informatique, Université de Kinshasa, RD Congo. mabelarostin@yahoo.fr

\section{Ruffin-Benoît M. NGOIE}

Département de Mathématique, Institut Supérieur Pédagogique de Mbanza-Ngungu, RD Congo benoitmpoy@hotmail.com

\section{Fréderic MAKENGO MBAMBALU}

Facultés des Sciences économiques. Université Protestante au Congo. RD Congo. fredmakengo@hotmail.fr

\begin{abstract}
Air controllers encounter aeronautical problems everyday. Those problems complexity is growing as the latter problems emerge in aerial navigations sectors at the time of the air traffic assignment. As a long time as the number of aircraft in a sector is high, the controller-related load will increase in a nonlinear way. Currently, one counts, on the congolese territory, and especially in the vicinity of areas with wars, many planes movements. This would represent in a near future a difficult bulk of control for controllers. In order to avoid saturation in sectors, the congolese airspace must be divided in increasingly small sectors while distributing the workloads. To clarify the analysis, one is interested in the multicriteria optimization which deals with the case of the simultaneous presence of several objectives by the preferential reference of dominance method proposed by Joseph Okitonyumbe and Berthold Ulungu [4]. The latter method is based on a new characterization of the efficient solutions by building the probable assignments in order to minimize the load of control in the sector.
\end{abstract}

Keywords: Preferential reference of dominance method, Simultaneous Optimization, Assignment Multiobjective Problem, Sectorization.

\section{INTRODUCTION}

In comparison with traditional problems of combinatorial optimization, one counts assignment problems which belong to the class $\mathrm{P}$. The latter includes mono-objective problems and is one of easiest combinatorial optimization among the nine. Its linear relaxation is not restrictive to solve because it checks the property of total one-peakedness.

On the other hand, taking into account several criteria generates a new surprising difficulty [4]. This difficulty remains topical in the congolese air grid system for the multi - objective problem of sectorization and air traffic assignment in a simultaneous way. This problem to be solved can be frequently expressed in the general form of an optimization problem, in which one must define an objective-function that one seeks to minimize with regard to all the concerned parameters. There are many traditional optimization methods to solve such problems. Those methods can be carried out when some mathematical conditions are satisfied.

Through this study, we make easy the resolution of these problems by the construction of some efficient assignments by the preferential reference of dominance method. For that, one minimizes two criteria: the number of sectors and the time of travel in a sector. The first involves the maximization of the covered distance in the sector. 


\section{Method of Preferential Reference of Dominance (MPRD)[4]}

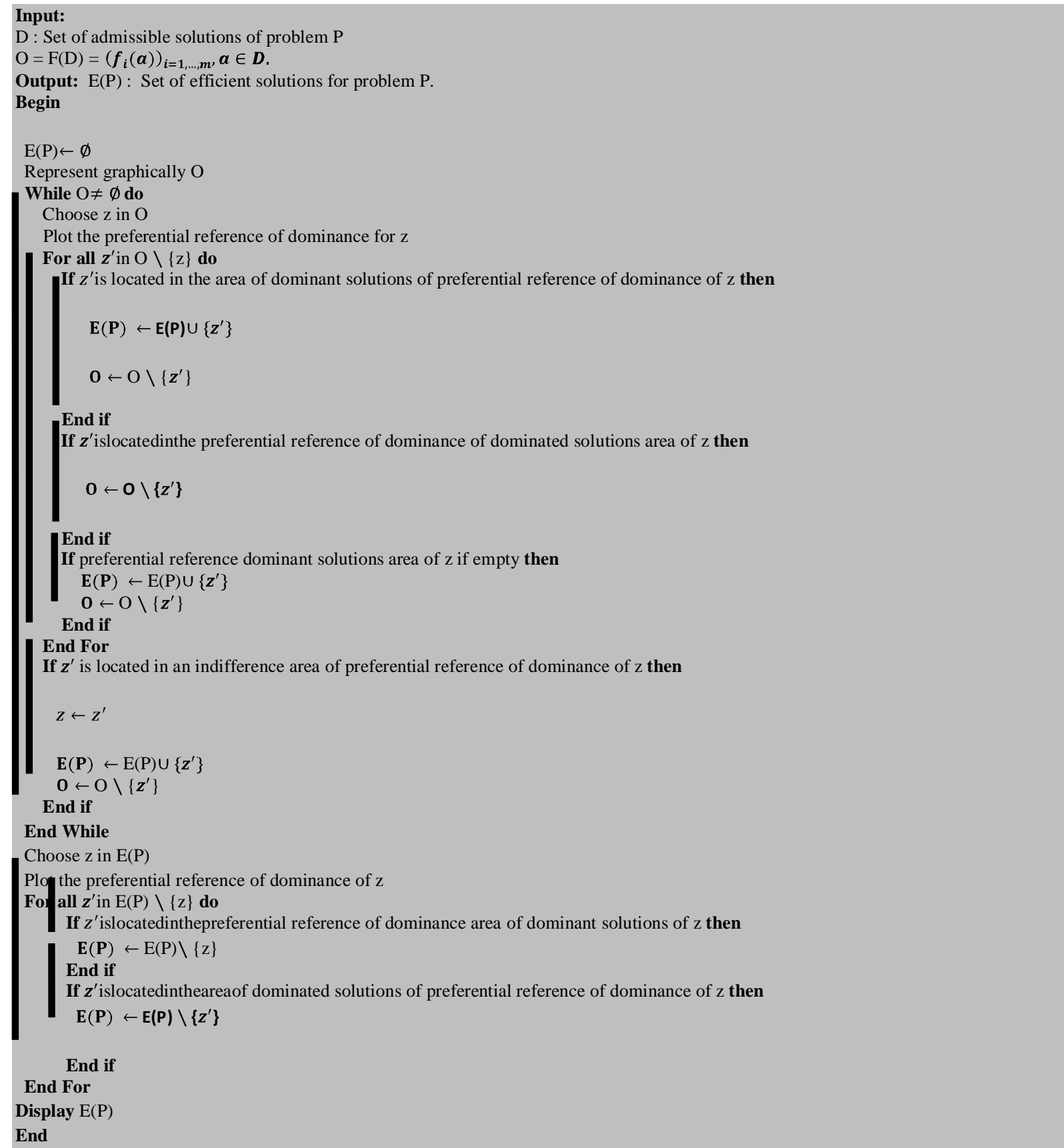

\section{Multicriteria Problems of Assignment}

The multicriteria problem of assignment consists in assigning $\mathrm{n}$ people to $\mathrm{n}$ tasks, in an optimal way. Let us indicate by $i=1 \ldots, n$ the people having the responsibility of control in a sector and by $j=1 \ldots$, $\mathrm{n}$ the number of the sectors; $c_{i j}^{k}$ the coefficient of assignment of air controller $\mathrm{i}$ to the sector $\mathrm{j}$, of $\mathrm{k}^{\text {th }}$ objective. These values can be a cost of assignment from i to $j$, one duration of assignment, an index preferably expressed by controller i or one factor of reliability [6].

Mathematical formulation of the problem: 


$$
(P): \begin{cases}\text { "min" } F(X)=\left(f_{k}(X)\right) \sum_{i=1}^{n} \sum_{j=1}^{n}{ }^{r}{ }^{r}{ }_{i j} x_{i j} & r=1, \ldots, m \\ \sum_{i=1}^{n} x_{i j}=1 & j=1, \ldots, n \\ \sum_{j=1}^{n} x_{i j}=1 & i=1 ; \ldots, n \\ x_{i j}=(0,1) & i, j=1, \ldots, n\end{cases}
$$

Where $x_{i j}=\left\{\begin{array}{c}1, \text { if } i \text { is assigned to } j \\ 0, \text { else }\end{array}\right.$

The other constraints express that a task is carried out by only one controller and reciprocally $[5,6]$.

\section{Problems to be Solved}

\subsection{Problem of sectorization}

From the knowledge of a network with two dimensions, in comparison with the load of control in the sector, one proposes to find a balanced sectorization outcome with a homogeneous output of the teams of control with responsibility of the whole airspace.

So that a controller can act easily on the present flights in his sector, the latter must remain a sufficient time equal to the time of safety. A plane will have to remain a minimum time in each sector which it crosses.

\section{Formulation of the problem}

Let be a grid system in a space with two dimensions on which a distribution of flow produces a load of control distributed in the whole airspace. One proposes to sectorize this space in $\mathrm{k}$ balanced sectors in terms of control responsibility while minimizing coordinations. This sectorization will have to respect some constraints: minimum residence time, convexity of road, ... [1, 2].

\subsection{Problem of traffic assignment}

The purpose of the traffic assignment is to define the air routes in order to reduce the control responsibility. Thus to increase the capacity of the system.

\section{Formulation of the problem}

Let be a grid system in a space with two dimensions, divided into k sectors. One wishes to assign the traffic between each pair origin-destination, by respecting the constraint of equity, in order to minimize the load of control while reducing the induced extensions.

From where the problem of sectorization is then broken up into two completely independent subproblems, corresponding to the two laid down objectives which are:

- Load balance in the sectors ;

- Minimization of coordinations [1,2].

\section{APPlication OF THE MPRD FOR THE MULTICRITERIA RESOlution OF THE Assignment Problems ANd Sectorization of CONgOlese AIR TrafFic}

The resolution of a multi-objective problem of assignment and that of the sectorization by the method of preferential reference of dominance is formulated as follows:

- determine the cloud of the points by allotting values to each objective; 
- apply, as many as possible the MPRD to this group of points to generate, by level, the sets of the efficient solutions $E_{i}(\mathrm{P})$;

- build the potentially efficient assignments with the $E_{i}(\mathrm{P})$ by giving priority to the smallest indices i;

- filter the built assignments by once more applying the MPRD to generate the set of the efficient solutions.

\subsection{Fleet structure of the company Fly CAA}

The fleet of the African air company is primarily made up of the planes with short and average following mails: two FOKKER 50 registered 9Q-CAB, 9Q - CCI, 1 FOKKER 100 registered 9QCHO and 3 airbus registered 320 9Q-CAT, 9Q-CCA, 0Q-CCO.

\subsection{Assignment in the internal network}

Fly CAA ensures the service road on 24 destinations located at interior of the Democratic Republic of Congo. In comparison with the airbus planes the exploited lines are as follows:

$$
\begin{gathered}
\text { Kinshasa- Mbandaka - Gemena } \\
\text { Kinshasa- Kisangani - Goma } \\
\text { Kinshasa- Mbuji-Mayi- Lubumbashi } \\
\text { Kinshasa- Kananga - Lubumbashi } \\
\text { Kinshasa- Lubumbashi. }
\end{gathered}
$$

This represents a load of control compared to the existing network [3].

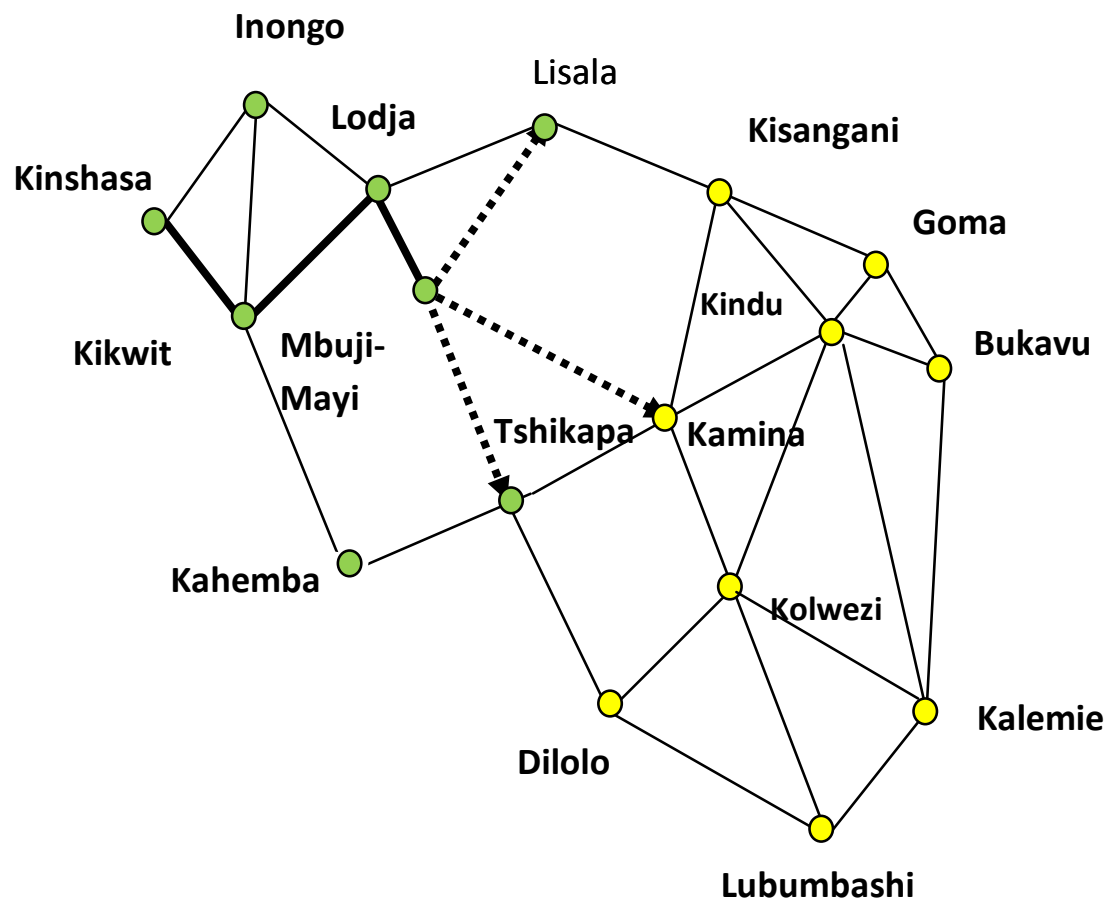

\subsection{Didactic Example}

In order to regularize the situation of congolese air traffic, Fly CAA which has its airbus planes and the bodies in charge of control of air traffic assign the agents of control in sectors at the end of the existing axial network. In front of a situation, these agents do not react in the same way in terms of loads of coordination and do not have same competences, same experience and the same contract of employment. The weights granted to the assignment of a controller ito sector $\mathrm{j}$ are given by the matrix $\mathrm{E}, \mathrm{F}$ and the levels of incompetence corresponding to the loads by the matrices $\mathrm{G}, \mathrm{H}$. 
Simultaneous Optimization: Sectorization and Congolese Air Traffic Assignment by the Method of Preferential Reference of Dominance

Matrix E Costs of origin assignment

\begin{tabular}{|c|c|c|c|}
\hline & $S_{1}$ & $S_{2}$ & $S_{3}$ \\
\hline$C_{1}$ & 6 & 4 & 1 \\
\hline$C_{2}$ & 7 & 2 & 3 \\
\hline$C_{3}$ & 1 & 8 & 4 \\
\hline
\end{tabular}

Matrix F: costs of destination assignment

\begin{tabular}{|c|c|c|c|}
\hline & $S_{1}$ & $S_{2}$ & $S_{3}$ \\
\hline$C_{1}{ }^{\prime}$ & 6 & 3 & 2 \\
\hline$C_{2}{ }^{\prime}$ & 5 & 1 & 3 \\
\hline$C_{3}{ }^{\prime}$ & 2 & 7 & 4 \\
\hline
\end{tabular}

Matrix G: Levels of origin incompetence

\begin{tabular}{|c|c|c|c|}
\hline & $S_{1}$ & $S_{2}$ & $S_{3}$ \\
\hline$C_{1}$ & 3 & 1 & 3 \\
\hline$C_{2}$ & 2 & 2 & 2 \\
\hline$C_{3}$ & 1 & 3 & 4 \\
\hline
\end{tabular}

Matrix H: Levels of destination incompetence

\begin{tabular}{|c|c|c|c|}
\hline & $S_{1}$ & $S_{2}$ & $S_{3}$ \\
\hline$C_{1}$, & 2 & 4 & 1 \\
\hline$C_{2}$, & 1 & 2 & 3 \\
\hline$C_{3}$, & 2 & 1 & 1 \\
\hline
\end{tabular}

\section{Resolution of the problem}

It is about a problem of simultaneous minimization of two objectives: the travelling time in the sector and the number of sectors. Nevertheless, the version min-min of the MPRD does not enable us to install a matrix I of points cloud in the space of the objectives due to the fact that the traffic varies simultaneously in a space with two dimensions: the pair origin - destination.

From where we enrich this exact method in the following way:

Before installing matrix I of cloud, we start by adding the costs with assignment origin-destination and the levels of incompetence in order to obtain two new matrices $\mathrm{J}$ and $\mathrm{K}$ (respectively costs of assignment and levels of incompetence) and to amalgamate both to have I.

Matrix I of pointscloud (1)

\begin{tabular}{|c|c|c|c|}
\hline & $S_{1}$ & $S_{2}$ & $S_{3}$ \\
\hline$C_{1,1}$, & $(12,5)$ & $(7,5)$ & $(3,4)$ \\
\hline$C_{2,2}$, & $(12,3)$ & $(3,4)$ & $(6,5)$ \\
\hline$C_{3,3}$ & $(3,3)$ & $(15,4)$ & $(8,5)$ \\
\hline
\end{tabular}

\section{Set of potentially efficient solutions by level}

The application of this method on this group of points makes it possible to release the set of efficient solutions of first level. The suppression of the points of this unit and a second application of the MPRD on the leftover of the points gives us the set of efficient solutions of second level and so on.

$$
\begin{aligned}
& E_{1}(P)=\{(3,3)\} \\
& E_{2}(P)=\{(3,4),(12,3)\} \\
& E_{3}(P)=\{(15,4),(6,5)\} \\
& E_{4}(P)=\{(7,5)\} \\
& E_{5}(P)=\{(8,5)\} \\
& E_{6}(P)=\{(12,5)\}
\end{aligned}
$$




\section{Probably efficient assignments}

The assignments are built while starting with the elements of the set of efficient solutions of the first level to elements of the set of efficient solutions of the last level.

However, it is possible to accept even an assignment in the set of efficient solutions of last level with an aim of the intensification and from diversification in research because filtration will come to decide between the solutions. What leads to :

$$
\begin{array}{ll}
C_{3,3}{ }^{\prime}-S_{1} ; C_{2,2}{ }^{\prime}-S_{2} ; C_{1,1}{ }^{\prime}-S_{3} & \mathrm{~A}(9,11) \\
C_{3,3}{ }^{\prime}-S_{1} ; C_{2,2}{ }^{\prime}-S_{3} ; C_{1,1}{ }^{\prime}-S_{2} & \mathrm{~B}(16,13) \\
C_{2,2}{ }^{\prime}-S_{2} ; C_{3,3^{\prime}}-S_{3} ; C_{1,1}{ }^{\prime}-S_{1} & \mathrm{C}(23,14) \\
C_{2,2}{ }^{\prime}-S_{1} ; C_{3,3}{ }^{\prime}-S_{2} ; C_{1,1}{ }^{\prime}-S_{3} & \mathrm{D}(30,11) \\
C_{2,2}{ }^{\prime}-S_{1} ; C_{1,1}{ }^{\prime}-S_{2} ; C_{3,3}{ }^{\prime}-S_{3} & \mathrm{E}(27,13) \\
C_{3,3}{ }^{\prime}-S_{2} ; C_{2,2^{\prime}}-S_{3} ; C_{1,1}{ }^{\prime}-S_{1} & \mathrm{~F}(33,14)
\end{array}
$$

Let us apply the MPRD to filter the assignments:

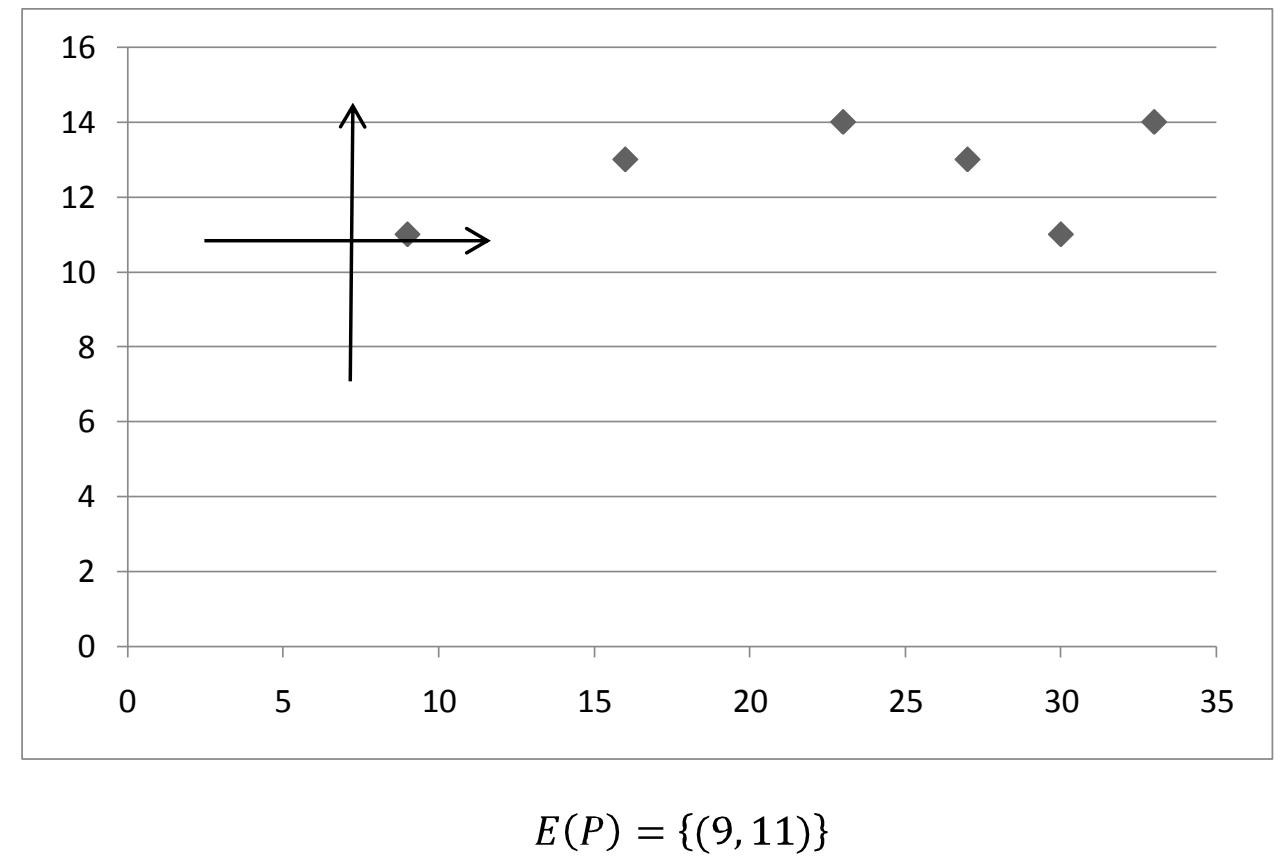

Corresponding to the assignment : $C_{3,3}{ }^{\prime}-S_{1} ; C_{2,2}{ }^{\prime}-S_{2} ; C_{1,1}{ }^{\prime}-S_{3}$

Matrix I of cloud of the points(2)

\begin{tabular}{|c|c|c|c|}
\hline & $S_{1}$ & $S_{2}$ & $S_{3}$ \\
\hline$C_{1,2}$, & $(11,4)$ & $(5,3)$ & $(4,6)$ \\
\hline$C_{2,3}$, & $(9,4)$ & $(9,3)$ & $(7,3)$ \\
\hline$C_{3,1}$, & $(7,3)$ & $(11,7)$ & $(6,5)$ \\
\hline
\end{tabular}

\section{Set of potentially efficient solutions by level}

The application of this method on this group of points makes it possible to release the set of efficient solutions of first level. The suppression of the points of this unit and a second application of the MPRD on the leftover of the points gives us the set of efficient solutions of second level and so on. 


$$
\begin{aligned}
& E_{1}(P)=\{(5,3)\} \\
& E_{2}(P)=\{(7,3)\} \\
& E_{3}(P)=\{(9,3)\} \\
& E_{4}(P)=\{(4,6),(6,5),(9,4)\} \\
& E_{5}(P)=\{(11,4)\} \\
& E_{6}(P)=\{(11,7)\}
\end{aligned}
$$

\section{Probably efficient assignments}

The assignments are built while starting with the elements of the set of efficient solutions of the first level to elements of the set of efficient solutions of the last level.

However, it is possible to accept even an assignment in the whole of efficient solutions of last level with an aim of the intensification and from diversification in research because filtration will come to decide between the solutions. What leads to:

$$
\begin{array}{ll}
C_{1,2}{ }^{\prime}-S_{2} ; C_{2,3}{ }^{\prime}-S_{3} ; C_{3,1}{ }^{\prime}-S_{1} & \mathrm{~A}(19,9) \\
C_{1,2}{ }^{\prime}-S_{2} ; C_{3,1}{ }^{\prime}-S_{3} ; C_{2,3}{ }^{\prime}-S_{1} & \mathrm{~B}(15,12) \\
C_{1,2}{ }^{\prime}-S_{2} ; C_{2,3}{ }^{\prime}-S_{1} ; C_{3,1}{ }^{\prime}-S_{3} & \mathrm{C}(20,12) \\
C_{2,3}{ }^{\prime}-S_{3} ; C_{1,2}{ }^{\prime}-S_{1} ; C_{3,1}{ }^{\prime}-S_{2} & \mathrm{D}(26,14) \\
C_{2,3}{ }^{\prime}-S_{2} ; C_{1,2}{ }^{\prime}-S_{3} ; C_{3,1}{ }^{\prime}-S_{1} & \mathrm{E}(20,12) \\
C_{2,3}{ }^{\prime}-S_{2} ; C_{3,1}{ }^{\prime}-S_{3} ; C_{1,2}{ }^{\prime}-S_{1} & \mathrm{~F}(26,12) \\
C_{2,3}{ }^{\prime}-S_{2} ; C_{1,2}{ }^{\prime}-S_{1} ; C_{3,1}{ }^{\prime}-S_{3} & \mathrm{G}(27,12) \\
C_{2,1}{ }^{\prime}-S_{3} ; C_{2,3}{ }^{\prime}-S_{1} ; C_{3,1}{ }^{\prime}-S_{2} & \mathrm{H}(24,17)
\end{array}
$$

Let us apply the MPRD to filter the assignments:

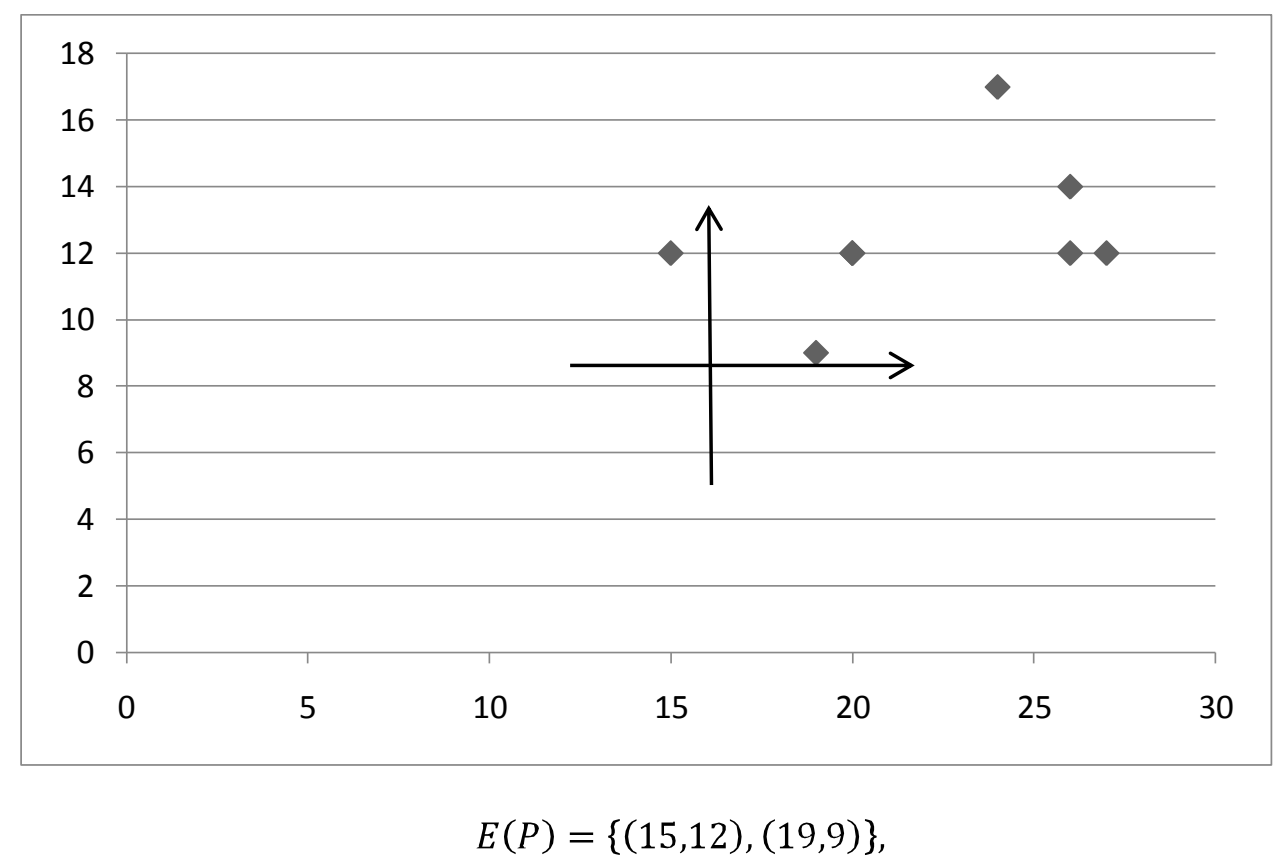

Corresponding to the assignments: 


$$
\begin{aligned}
& C_{1,2}{ }^{\prime}-S_{2} ; C_{2,3}{ }^{\prime}-S_{3} ; C_{3,1}{ }^{\prime}-S_{1} \\
& C_{1,2}{ }^{\prime}-S_{2} ; C_{3,1}{ }^{\prime}-S_{3} ; C_{2,3}{ }^{\prime}-S_{1}
\end{aligned}
$$

Matrix I of cloud of points (3)

\begin{tabular}{|c|c|c|c|}
\hline & $S_{1}$ & $S_{2}$ & $S_{3}$ \\
\hline$C_{1,3}$, & $(8,5)$ & $(11,2)$ & $(5,4)$ \\
\hline$C_{2,1}$, & $(13,4)$ & $(5,6)$ & $(5,3)$ \\
\hline$C_{3,2}$ & $(6,2)$ & $(9,5)$ & $(7,7)$ \\
\hline
\end{tabular}

\section{Set of potentially efficient solutions by level}

The application of this method on this group of points makes it possible to release the set of efficient solutions of first level. The suppression of the points of this unit and a second application of the MPRD on the leftover of the points gives us the whole of effective solutions of second level and so on.

$$
\begin{aligned}
& E_{1}(P)=\{(6,2) ;(5,3)\} \\
& E_{2}(P)=\{(5,4) ;(11,2)\} \\
& E_{3}(P)=\{(13,4) ;(8,5) ;(5,6)\} \\
& E_{4}(P)=\{(9,5)\} \\
& E_{5}(P)=\{(7,7)\}
\end{aligned}
$$

\section{Probably efficient assignments}

$$
\begin{array}{ll}
C_{3,2}{ }^{\prime}-S_{1} ; C_{2,1}{ }^{\prime}-S_{3} ; C_{1,3}{ }^{\prime}-S_{2} & \mathrm{~A}(22,7) \\
C_{3,2}{ }^{\prime}-S_{1} ; C_{1,3}{ }^{\prime}-S_{3} ; C_{2,1}{ }^{\prime}-S_{2} & \mathrm{~B}(16,12) \\
C_{2,1}{ }^{\prime}-S_{3} ; C_{1,3}{ }^{\prime}-S_{1} ; C_{3,2}{ }^{\prime}-S_{2} & \mathrm{C}(22,13) \\
C_{1,3}{ }^{\prime}-S_{3} ; C_{2,1}{ }^{\prime}-S_{1} ; C_{3,2}{ }^{\prime}-S_{2} & \mathrm{D}(27,13)
\end{array}
$$

Let us apply the MRPD to filter the assignments:

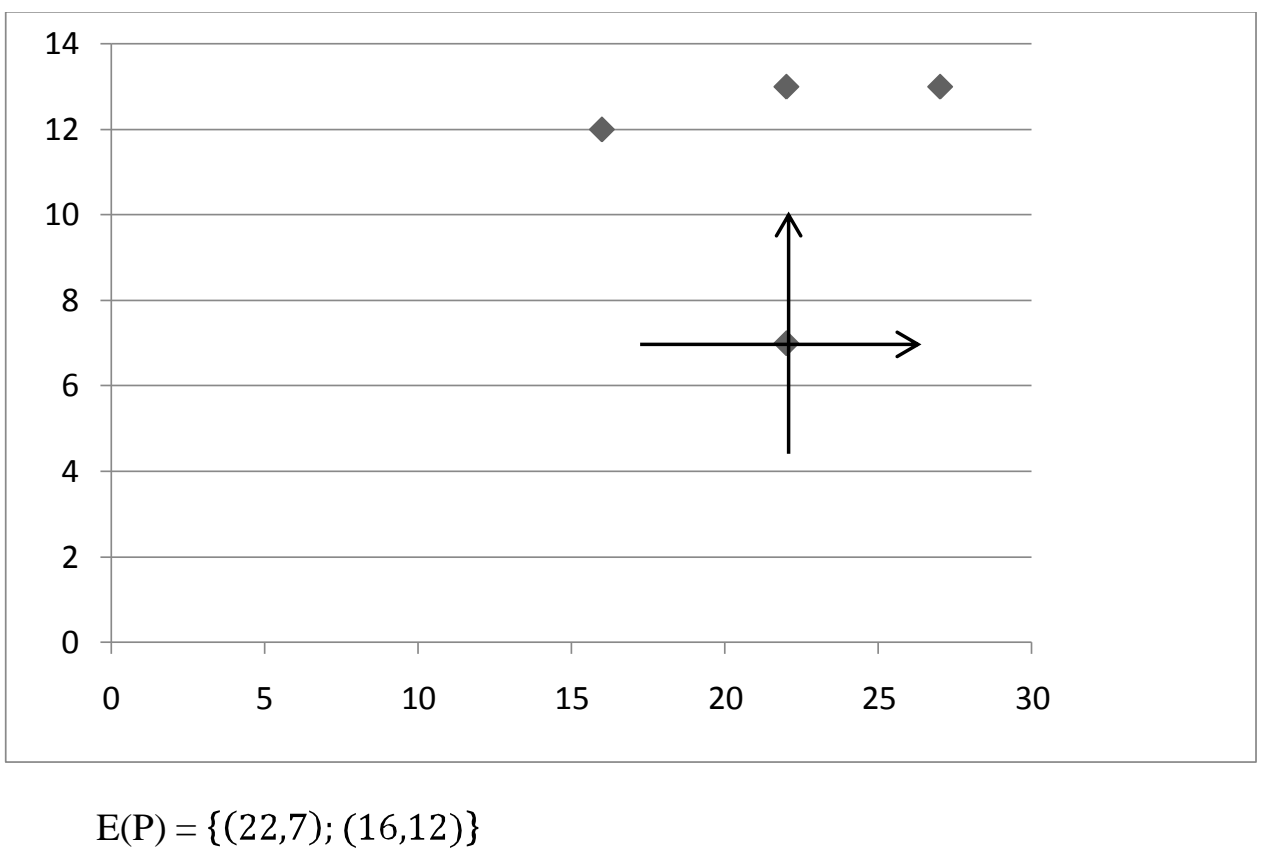

Corresponding to the assignments:

$$
C_{3,2}{ }^{\prime}-S_{1} ; C_{2,1}{ }^{\prime}-S_{3} ; C_{1,3}{ }^{\prime}-S_{2}
$$


Simultaneous Optimization: Sectorization and Congolese Air Traffic Assignment by the Method of Preferential Reference of Dominance

$$
C_{3,2}{ }^{\prime}-S_{1} ; C_{1,3}{ }^{\prime}-S_{3} ; C_{2,1}{ }^{\prime}-S_{2}
$$

Matrix I of cloud of points (4)

\begin{tabular}{|c|c|c|c|}
\hline & $S_{1}$ & $S_{2}$ & $S_{3}$ \\
\hline$C_{1,1}$, & $(12,5)$ & $(7,5)$ & $(3,4)$ \\
\hline$C_{2,3}$, & $(9,4)$ & $(9,3)$ & $(7,3)$ \\
\hline$C_{3,2}$ & $(6,2)$ & $(9,5)$ & $(7,7)$ \\
\hline
\end{tabular}

Set of potentially effective solutions by level

$$
\begin{gathered}
\mathrm{E}_{1}(\mathrm{P})=\{(6,2) ;(3,4)\} \\
\mathrm{E}_{2}(\mathrm{P})=\{(7,3)\} \\
\mathrm{E}_{3}(\mathrm{P})=\{(9,3) ;(7,5)\} \\
\mathrm{E}_{4}(\mathrm{P})=\{(9,4) ;(7,7)\} \\
\mathrm{E}_{5}(\mathrm{P})=\{(9,5)\} \\
\mathrm{E}_{6}(\mathrm{P})=\{(12,5)\}
\end{gathered}
$$

Probably efficient assignments

$$
\begin{array}{ll}
C_{3,2}{ }^{\prime}-S_{1} ; C_{1,1}{ }^{\prime}-S_{3} ; C_{2,3}{ }^{\prime}-S_{2} & \mathrm{~A}(18,9) \\
C_{3,2}{ }^{\prime}-S_{1} ; C_{2,3}{ }^{\prime}-S_{3} ; C_{1,1}{ }^{\prime}-S_{2} & \mathrm{~B}(20,10) \\
C_{1,1}{ }^{\prime}-S_{3} ; C_{2,3}{ }^{\prime}-S_{1} ; C_{3,2}{ }^{\prime}-S_{2} & \mathrm{C}(21,13)
\end{array}
$$

Let us apply the MRPD to filter the assignments:

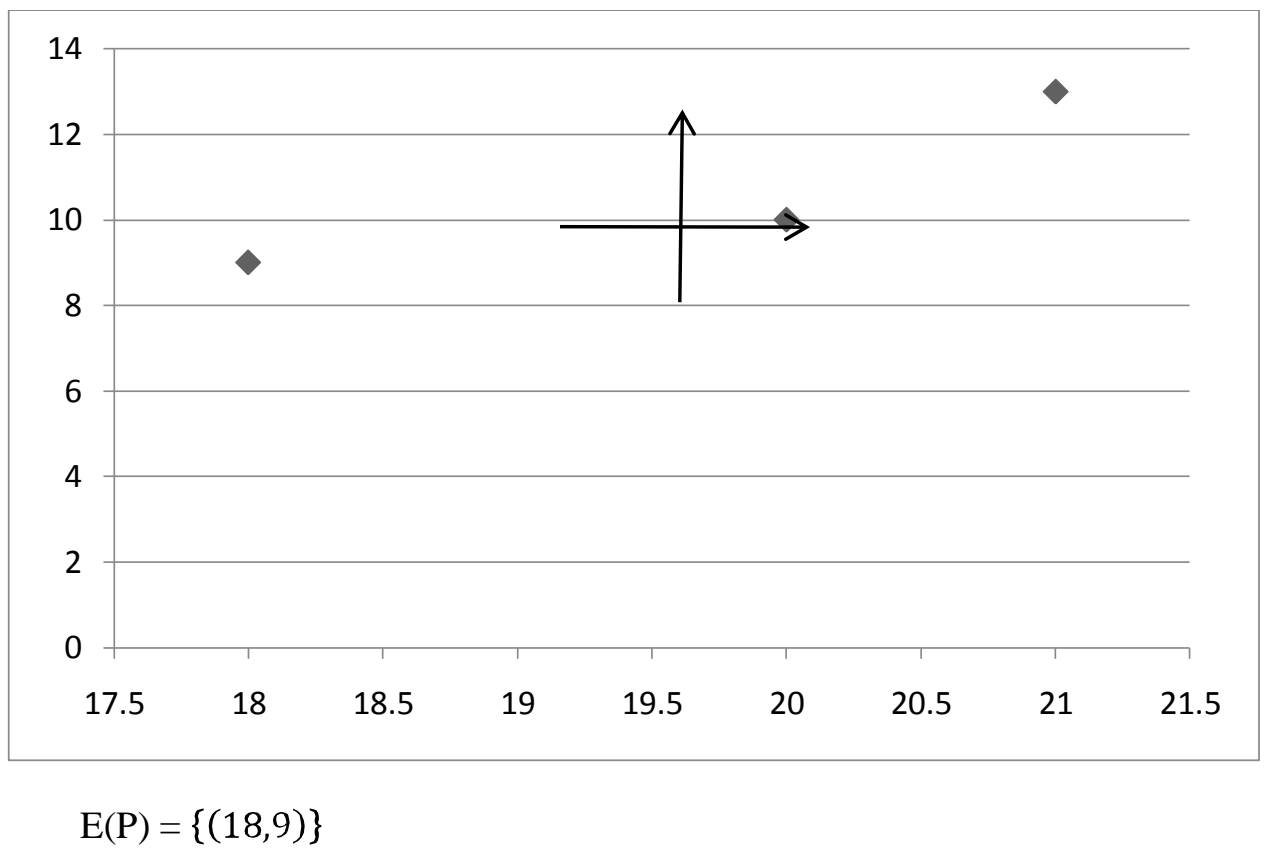

Corresponding to the assignment:

$$
C_{3,2}{ }^{\prime}-S_{1} ; C_{1,1}{ }^{\prime}-S_{3} ; C_{2,3}{ }^{\prime}-S_{2}
$$

Matrix I of cloud of points (5)

\begin{tabular}{|c|c|c|c|}
\hline & $S_{1}$ & $S_{2}$ & $S_{3}$ \\
\hline$C_{1,3}$, & $(8,5)$ & $(11,2)$ & $(5,4)$ \\
\hline$C_{2,2}$, & $(12,3)$ & $(3,4)$ & $(6,5)$ \\
\hline$C_{3,1}$ & $(7,3)$ & $(11,7)$ & $(6,5)$ \\
\hline
\end{tabular}

Set of potentially effective solutions by level 


$$
\begin{gathered}
\mathrm{E}_{1}(\mathrm{P})=\{(11,2) ;(7,3) ;(3,4)\} \\
\mathrm{E}_{2}(\mathrm{P})=\{(12,3) ;(5,4)\} \\
\mathrm{E}_{3}(\mathrm{P})=\{(6,5)\} \\
\mathrm{E}_{4}(\mathrm{P})=\{(8,5)\} \\
\mathrm{E}_{5}(\mathrm{P})=\{(11,7)\}
\end{gathered}
$$

Probably efficient assignments

$$
\begin{array}{ll}
C_{1,3}{ }^{\prime}-S_{2} ; C_{3,1}{ }^{\prime}-S_{1} ; C_{2,2}{ }^{\prime}-S_{3} & \mathrm{~A}(24,10) \\
C_{1,3}{ }^{\prime}-S_{2} ; C_{2,2}{ }^{\prime}-S_{1} ; C_{3,1}{ }^{\prime}-S_{3} & \mathrm{~B}(29,10) \\
C_{3,1}{ }^{\prime}-S_{1} ; C_{2,2}{ }^{\prime}-S_{2} ; C_{1,3}{ }^{\prime}-S_{3} & \mathrm{C}(15,11) \\
C_{2,2}{ }^{\prime}-S_{2} ; C_{1,3}{ }^{\prime}-S_{1} ; C_{3,1}{ }^{\prime}-S_{3} & \mathrm{D}(17,14)
\end{array}
$$

Let us apply the MPRD to filter the assignments:

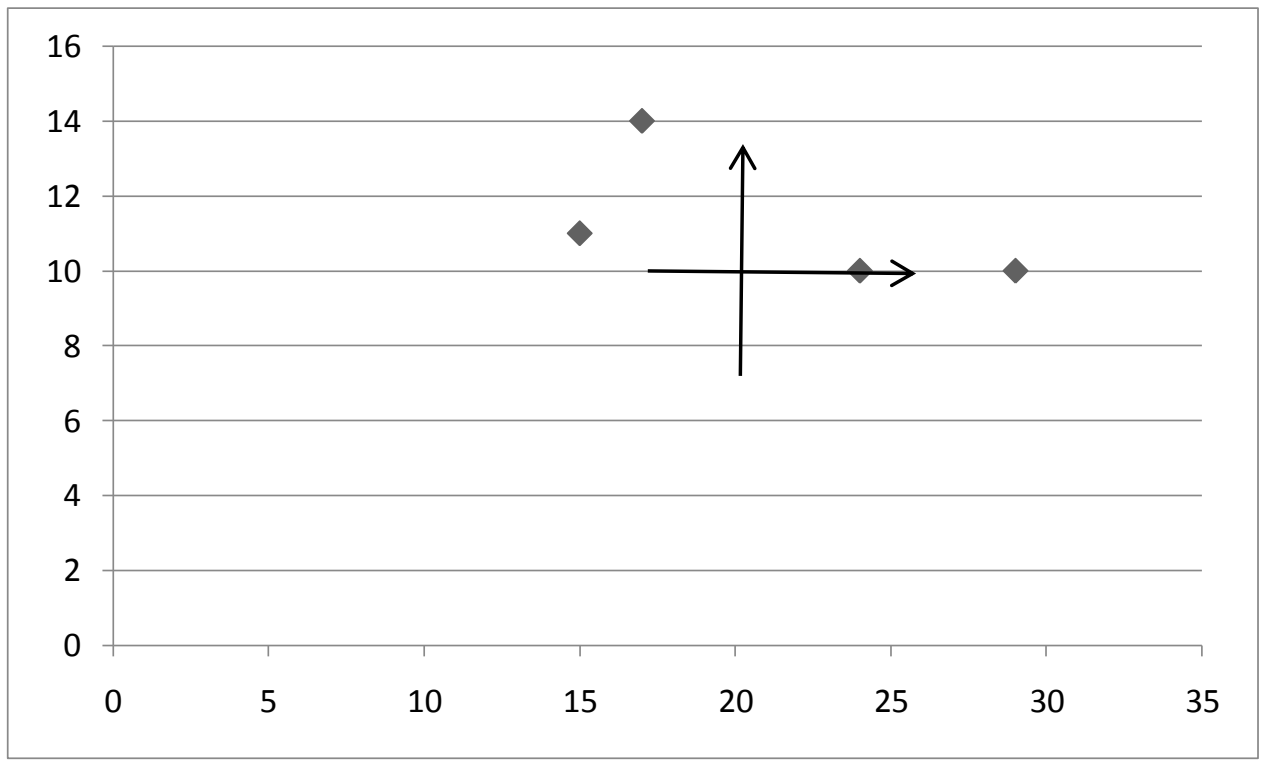

$$
\mathrm{E}(\mathrm{P})=\{(15,11) ;(24,10)\}
$$

Corresponding to the assignments:

$$
\begin{aligned}
& C_{3,1}{ }^{\prime}-S_{1} ; C_{2,2}{ }^{\prime}-S_{2} ; C_{1,3}{ }^{\prime}-S_{3} \\
& C_{1,3}{ }^{\prime}-S_{2} ; C_{3,1}{ }^{\prime}-S_{1} ; C_{2,2}{ }^{\prime}-S_{3}
\end{aligned}
$$

Matrix I of cloud of points (6)

\begin{tabular}{|c|c|c|c|}
\hline & $S_{1}$ & $S_{2}$ & $S_{3}$ \\
\hline$C_{1,2}$, & $(11,4)$ & $(5,3)$ & $(4,6)$ \\
\hline$C_{2,1}$, & $(13,4)$ & $(5,6)$ & $(5,3)$ \\
\hline$C_{3,3}$ & $(3,3)$ & $(15,4)$ & $(8,5)$ \\
\hline
\end{tabular}

Set of potentially efficient solutions by level

$$
\begin{gathered}
\mathrm{E}_{1}(\mathrm{P})=\{(3,3)\} \\
\mathrm{E}_{2}(\mathrm{P})=\{(5,3) ;(4,6)\} \\
\mathrm{E}_{3}(\mathrm{P})=\{(11,4) ;(8,5) ;(5,6)\} \\
\mathrm{E}_{4}(\mathrm{P})=\{(13,4)\} \\
\mathrm{E}_{5}(\mathrm{P})=\{(15,4)\}
\end{gathered}
$$


Simultaneous Optimization: Sectorization and Congolese Air Traffic Assignment by the Method of Preferential Reference of Dominance

Probably efficient assignments

$$
\begin{array}{ll}
C_{3,3}{ }^{\prime}-S_{1} ; C_{2,1}{ }^{\prime}-S_{3} ; C_{1,2}{ }^{\prime}-S_{2} & \mathrm{~A}(13,9) \\
C_{3,3}{ }^{\prime}-S_{1} ; C_{2,1}{ }^{\prime}-S_{2} ; C_{1,2}{ }^{\prime}-S_{3} & \mathrm{~B}(12,15) \\
C_{1,2}{ }^{\prime}-S_{2} ; C_{2,1}{ }^{\prime}-S_{1} ; C_{3,3}{ }^{\prime}-S_{3} & \mathrm{C}(26,12) \\
C_{2,1}{ }^{\prime}-S_{3} ; C_{1,2}{ }^{\prime}-S_{1} ; C_{3,3}{ }^{\prime}-S_{2} & \mathrm{D}(31,11)
\end{array}
$$

Let us apply the MPRD to filter the assignments:

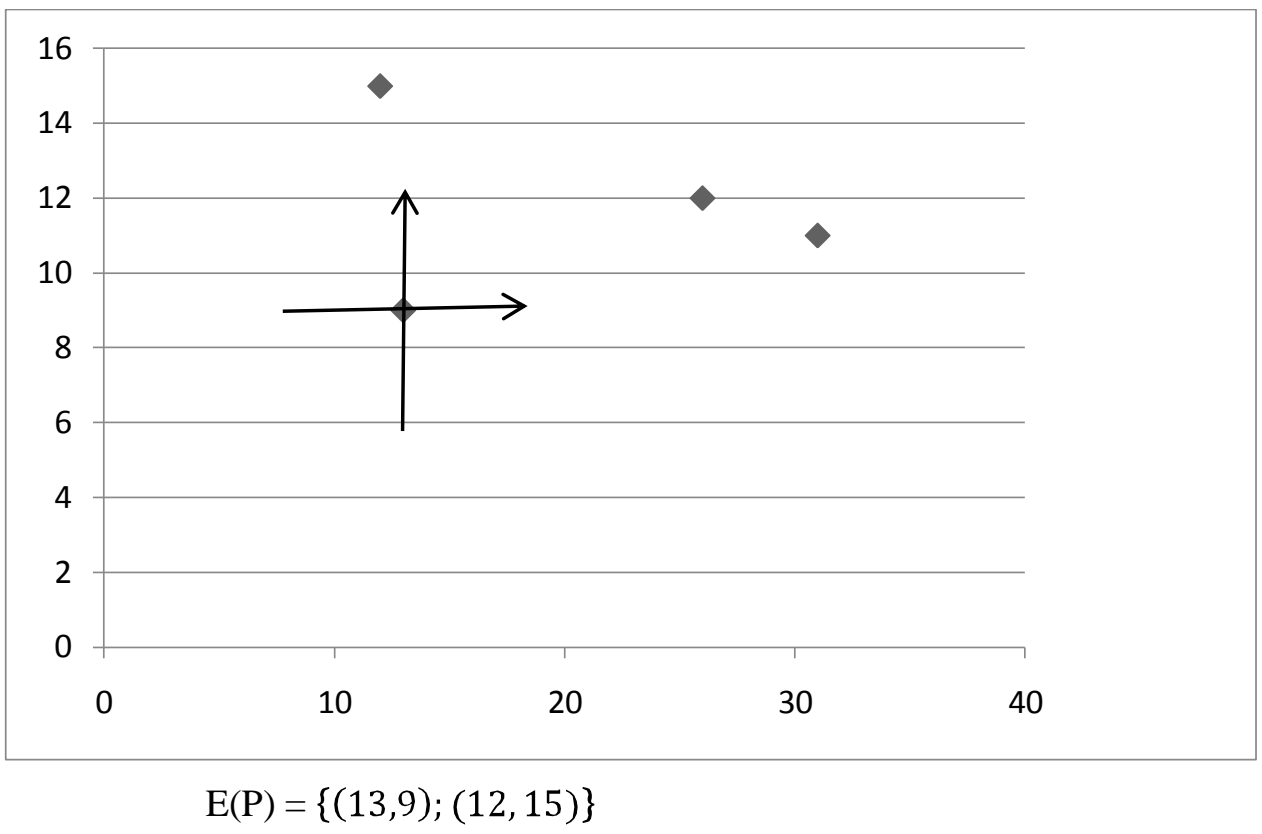

Corresponding to the assignments:

$$
\begin{aligned}
& C_{3,3}{ }^{\prime}-S_{1} ; C_{2,1}{ }^{\prime}-S_{3} ; C_{1,2}{ }^{\prime}-S_{2} \\
& C_{3,3}{ }^{\prime}-S_{1} ; C_{2,1}{ }^{\prime}-S_{2} ; C_{1,2}{ }^{\prime}-S_{3}
\end{aligned}
$$

\section{RESUlTS AND DisCUSSION}

The union of the efficient sets of solutions obtained for the six subproblems is:

$$
E(P)=\{(13,9) ;(12,15),(9,11),(15,12),(19,9),(22,7),(16,12),(18,9),(15,11),(24,10)\}
$$

The filtration of all these alternatives gives us the set of efficient solutions of the studied problem:

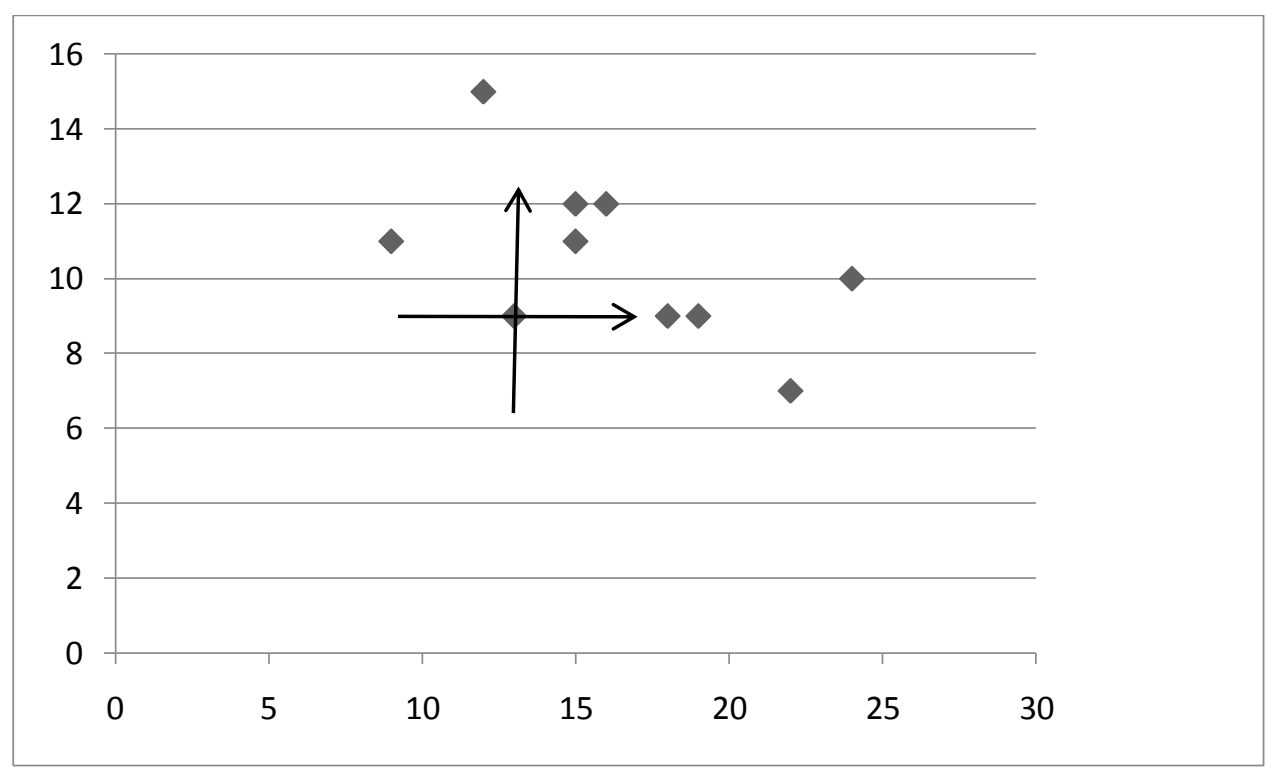


$\mathrm{E}(\mathrm{P})=\{(9,11),(13,9),(22,7)\}$

These solutions correspond respectively to the following assignments:

$C_{3,3}{ }^{\prime}-S_{1} ; C_{2,2}{ }^{\prime}-S_{2} ; C_{1,1}{ }^{\prime}-S_{3} \& C_{3,3}{ }^{\prime}-S_{1} ; C_{2,1}^{\prime}-S_{3} ; C_{1,2}^{\prime}-S_{2} \& C_{3,2}{ }^{\prime}-S_{1} ; \quad C_{2,1}^{\prime}-$ $S_{3} ; C_{1,3}^{\prime}-S_{2}$.

What means that controllers 3 and $3^{\prime}$ can be assigned to the first sector, 2 and $2^{\prime}$ with the second sector, 1 and $1^{\prime}$ to the third sector either 3 and $3^{\prime}$ to the first sector, $2^{\prime}$ and 1 to the third sector, $1^{\prime}$ and 2 to the second sector or 3 and $2^{\prime}$ to the first sector, $2^{\prime}$ and 1 to the third sector, $1^{\prime}$ and 3 to the second sector.

\section{Conclusion}

Through this article, we have proven the practical efficiency of the method of preferential reference of dominance on the simultaneous optimization of the sectorization and the assignment of the congolese air traffic. We adapted this method to the multicriteria resolution of the air traffic problems. We have to generate all the supported and not supported effective solutions supported for latter problems by a didactic example. The originality of this study is the simultaneous optimization of the sectorization and the assignment of the controllers; this assignment requires two controllers per sector. This led us to a small example with 3 sectors and six controllers with six combinations of the kind $c_{i i^{\prime}}{ }^{-}$ $S_{j}$ generating six various sets of efficient solutions whose filtration gives us the set of compromise to be proposed to the decision maker. A track of open research is the resolution of these problems under other skies.

\section{REFERENCES}

[1] Alliot J.M. Techniques d'optimisation stochastique appliquées à certains problèmes du trafic aérien, thèse de Doctorat, Paris, Octobre, 1998.

[2] Gianazza D. Optimisation des flux de trafic aérien. Thèse de doctorat, Institut National Polytechnique de Toulouse, Novembre 2004.

[3] Kikomba M. Exploration d'une extension du réseau de transport aérien congolais basée sur la programmation mathématique multicritère, Dissertation de DEA, Université Pédagogique Nationale, Kinshasa, Janvier 2013.

[4] Okitonyumbe J.Y.F. and Ulungu B. E.-L. Solving multiobjectif assignment problem and multiobjectif knapsack problem by dominance preferential mark method, MPRA paper $n^{\circ} 66125$, December, 2014. http://mpra.ub.uni-muenchen.de/66125/

[5] Jacques J. Recherche opérationnelle T1 : Méthodes d'optimisation,Ellipses 2012.

[6] Ulungu B. Optimisation Combinatoire Multicritère : Détermination de l'ensemble des solutions efficaces et méthodes interactives, $\mathrm{PhD}$ thesis, Université de Mons-Hainaut, Octobre 1993. 


\section{AUTHORS' BIOGRAPHY}

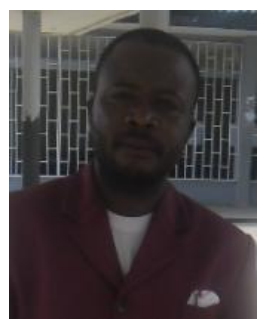

Michaël KIKOMBA KAHUNGU, is senior lecturer at Institut Supérieur des Techniques Appliquées de Kasangulu (Applied Enginneering College of Kasangulu), Kongo Central, DR Congo. He teaches Mathematics for engineers and Statistics.

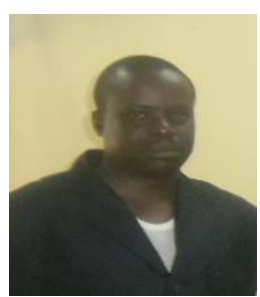

Rostin MABELA MAKENGO MATENDO, is Professor at University of Kinshasa (UNIKIN). He teaches Probability Calculus, Operations Research, Data Analysis and Mathematical Statistics.

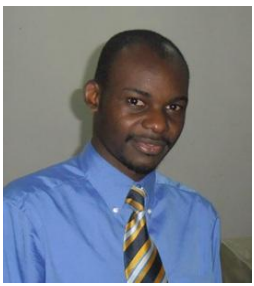

Ruffin-Benoît Ngoie Mpoy, is Senior Lecturer at Institut Supérieur Pédagogique de Mbanza-Ngungu (High Educational College of Mbanza-Ngungu), Democratic Republic of the Congo. He teaches Computer Programming, Numerical Analysis and Algorithms Theory. His main fields are Computational Social Choice Theory, Multiple Criteria Decision Aiding, and Games Theory. He proposed, in collaboration with Berthold Ulungu, the MMCM to slice between median and mean values. 